\title{
Serum Nickel Levels Compromise the Oxidative Status and Lung Functions in Ceramic Workers
}

\author{
Uzma Jabbar $^{1}$, Mazhar Mushtaq ${ }^{2, *}$, Javed Anver Qureshi ${ }^{3}$ \\ ${ }^{1}$ Biochemistry Department, Fatima Memorial Medical College, Lahore, Pakistan \\ ${ }^{2}$ Basic Medical Sciences Department, Sulaiman Al Rajhi University, Al-Bukayriah, Saudi Arabia \\ ${ }^{3}$ Nstitute of Molecular Biology and Biotechnology, The University of Lahore, ILahore, Pakistan
}

Email address:

dr_hcg@yahoo.com (M. Mushtaq)

${ }^{*}$ Corresponding author

\section{To cite this article:}

Uzma Jabbar, Mazhar Mushtaq, Javed Anver Qureshi. Serum Nickel Levels Compromise the Oxidative Status and Lung Functions in Ceramic Workers. International Journal of Environmental Chemistry. Vol. 5, No. 1, 2021, pp. 1-6. doi: 10.11648/j.ijec.20210501.11

Received: March 1, 2021; Accepted: March 17, 2021; Published: March 30, 2021

\begin{abstract}
Nickel, in the form of various alloys and compounds, has been in widespread commercial use for over 100 years. Several million workers worldwide are exposed to airborne fumes, dust, and mist containing nickel and its compounds. Further, exposures by inhalation, ingestion, or skin contact occur in nickel-producing industries, like mining, milling, melting, and refining, and in nickel-using industries, like electroplating, welding, and grinding. Insoluble nickel is the predominant exposure in nickel-producing industries, whereas soluble nickel is the predominant exposure in nickel-using industries like the ceramics industry. This study was designed to extrapolate the levels of serum nickel, antioxidant compounds, and stress markers and correlate them with lung function status in craft workers in the ceramics industry. The study included 50 fiber craft workers from the ceramics industry who met the inclusion criteria. The control group consisted of subjects from the general population with no disease. Blood samples from the workers were collected by a phlebotomist. The levels of nickel and biological antioxidants, i.e. serum glutathione (GSH) and stress marker malondialdehye (MDA), were determined. Estimation of oxidants and haptoglobin (Hp) levels were assessed. The level of nickel was measured by atomic absorption spectrophotometry. A spirometer was used to measure lung functions. The calculated levels of these parameters were compared with those in the control subjects. An overall increase in nickel and MDA levels and a decrease in GSH level were observed. When these workers were classified into groups, it was observed that prolonged employment in the ceramics industry was associated with an increased nickel concentration in the serum, which in turn increased oxidative stress biomarkers and thus decreased the antioxidant levels to the lower limit. The decrease in GSH level compromises lung function. Our findings of an increase the Hp level is noteworthy, as it increased by $89 \%$ in the group with over 10 years of service in the industry compared with the group working for less than 5 years. Prolonged exposure of nickel increases the oxidative stress, in terms of increased MDA level and decreased GSH level. These findings can compromise the lung function and increase the Hp level.
\end{abstract}

Keywords: Nickel, GSH, MDA, Haptoglobin, ROS, Antioxidant

\section{Introduction}

The health hazards associated with manmade fibers have been documented. For example, fiberglass and asbestos fibers may cause respiratory problems like asthma, pneumonia, and lung cancer $[1,2]$.

Nickel is a strong, lustrous, silvery-white metal that is a staple in our daily lives and can be found in a plethora of products, from the batteries that power television remotes to the stainless steel used to make kitchen sinks. Wide range of nickel applications is increasing on a daily basis. Nickel is a suitable element that can be combined with other elements to form alloys of various types, conferring them with heat and corrosion resistance and, above all, increasing their strength $[3,4]$.

Nickel salts are used in electroplating, coinage, electrical components, ceramics, pigments, intermediates like sinter nickel oxide, and also as nickel catalysts in the ceramics industry. Continuous exposure to nickel could result in a fatal 
outcome in individuals working in such environments [5].

The general population is exposed to low levels of nickel in the ambient air, water, food, and tobacco. Exposure may also occur via inhalation of ambient air and through percutaneous absorption [3, 6, 7]. The daily intake of nickel from food and beverages varies by foodstuff, country, age, and gender $[6,8]$. Data from a study in the US gave estimates of daily dietary intakes in the range of 101-162 $\mu \mathrm{g}$ /day for adults. Cohort studies have revealed that nickel (sulfidic oroxidic nickel) exposure increases the risk of lung cancer [8].

It has been proposed that the carcinogenicity induced by nickel may be due to the reduction of bio-reactive products, resulting in the production of Reactive Oxygen Species (ROS) [9-11]. These ROS may cause DNA damage, causing breaks in the DNA strands and oxidative DNA lesions. The cell membrane is most susceptible to free radicals, as it is prone to lipid peroxidation and can lead to the generation of mutagenic MDA [12].

The human body buffers the ROS produced to minimum and non-toxic levels. Reduced glutathione (GSH) plays a critical role as an antioxidant, and hence its serum levels are used as inverse markers of oxidative stress [13]. ROSinduced MDA formation another stress marker, the level of which directly correlates with stress. These biomarkers are important in the maintenance of homeostasis and functions of the cell, as well as for activating the body's immune system for scavenging ROS. Antioxidants, on the other hand, help to stabilize oxidative stress and abolish the toxic effects of heavy metals via synergic actions $[14,15]$.

Haptoglobin ( $\mathrm{Hp}$ ) has been classified as an acute-phase protein and is mainly attributed to decreased hemolysis. An increased level of $\mathrm{Hp}$ has also been implicated in some conditions like amyotrophic lateral sclerosis [16]. Increased expression of this acute-phase protein has also been validated in human lung cancer [17], and hence $\mathrm{Hp}$ (or more specifically its $\beta$ chain) has been confirmed as a serological biomarker in lung adenocarcinoma [18, 19]. Similarly, its binding with nickel has been identified in the serum of various animals, including humans [20,21]. A simultaneous increase in the levels of $\mathrm{Hp}$ and nickel was observed by Taruna Ikrar et al.

Oxidative stress occurs when the excessive formation of ROS overwhelms the antioxidant defense system, which is maintained in fine balance by antioxidants such as ascorbic acid, alpha-tocopherol, glutathione, carotenoids, flavonoids, and antioxidant enzymes including SOD, catalase, and glutathione peroxidase [12]. SOD scavenges toxic superoxide ions and converts them into hydrogen peroxide, which is maintained by the glutathione system, thus preventing the peroxidation of the cell membrane [22].

Occupational and Non-occupational exposure to Nickel have been studied in different industries and in different region. [23-25]. However, insufficient data is available for the ceramic industry workers and above all limited information is seen, of the direct impact of nickel on the oxidant status of the worker and their lung functions. This study was designed to extrapolate the levels of serum nickel, antioxidant compounds, and stress markers and correlate them with lung function status in craft workers in the ceramics industry.

\section{Materials and Methods}

The study included 50 craft workers of the ceramics industry. The workers received an explanation about their participation in the study, signed an informed consent, and completed a questionnaire with demographic data, and information related to other habits (like diet and smoking frequency), number of family members, education level, duration of employment in the ceramics industry, and most important is to take precautionary measures in the workplace. The study was carried out according to the tenets of the Declaration of Helsinki for human experimentation and was endorsed by the ethics committee of the University of Lahore, Pakistan, under the reference No. IMBB/UOL/191323.

Workers who were on prolonged treatment with corticosteroids or non-steroidal drugs were excluded from the study. Thirty controls with no history of working in any industry and with no disease were recruited as controls. A phlebotomist collected the random blood samples from all participants. Samples were directly collected in tubes with no additive, and were labeled with specific codes matching the worker's name in order to ensure anonymity. Blood was allowed to clot at room temperature and after 10-15 minutes, sample are centrifuged at $2000 \mathrm{~g}$ for 5 minutes. The resulting supernatant; serum was separated from the top, labeled and stored in refrigerator for further analysis.

\subsection{Measurements}

The levels of nickel in the serum of occupationally exposed workers were measured by flame atomic absorption spectrophotometry as described previously [26]. Antioxidant molecules GSH was measured by observing Tietze preparations [27] protocol of enzymatic recycling method. The stress marker MDA was assessed following the procedure used by Ohkawa et al. [28], and Hp levels were determined using the Human Hp ELISA Kit (Abcamab108856).

A spirometer was used to assess lung function by measuring the Forced Vital Capacity (FVC) and Forced Expiratory Volume in $1 \mathrm{~min}$ (FEV1). The ratio of these two parameters was compared with the normal ratio obtained in the control subjects.

\subsection{Statistical Analysis}

Data were analyzed using SPSS 21. Comparison of variables between the workers and the control subjects (normal values) was carried out using Student's $t$ tests. The comparison between the levels of serum nickel and oxidative stress markers (GSH and MDA) were explored. A value of $P<0.05$ was considered significant. 


\section{Results}

Table 1. Demographic variables of workers.

\begin{tabular}{|c|c|c|}
\hline \multicolumn{2}{|c|}{ Characteristic of variable } & $\begin{array}{l}\text { Number of } \\
\text { participants }\end{array}$ \\
\hline \multicolumn{2}{|c|}{ Number of workers between the age of 15 to 20} & 21 \\
\hline \multicolumn{2}{|c|}{ Number of workers between the age of 21 to 30} & 18 \\
\hline \multicolumn{2}{|c|}{ Number of workers between the age of 31 to 50} & 19 \\
\hline \multirow{3}{*}{ Duration of work } & 1 to 5 Year & 16 \\
\hline & 6 to 10 Year & 18 \\
\hline & $>10$ Year & 24 \\
\hline \multicolumn{2}{|c|}{ Smoker - 10 Cigarette/day } & 17 \\
\hline \multicolumn{2}{|c|}{ Healthy Habits - (Regular Walk, Exercise, Sports) } & 12 \\
\hline \multicolumn{2}{|c|}{ Number of workers with $\leq 4$ dependent family members } & 24 \\
\hline \multicolumn{2}{|c|}{ Number of workers with $\geq 6$ dependent family members } & 21 \\
\hline & 13 \\
\hline \multicolumn{2}{|c|}{$\begin{array}{c}\text { Number of workers with } \geq 8 \text { dependent family members } \\
\text { Dry Cough }\end{array}$} & 21 \\
\hline \multirow{4}{*}{ Chronic Symptoms } & Frequent Running Nose & 09 \\
\hline & Breath lessness end of the day & 7 \\
\hline & Headache & 10 \\
\hline & No Symptoms & 11 \\
\hline
\end{tabular}

Demographic data in table 1 shows, majority of the peoples engaged themselves at the work before the age of 20 . Out of the total 58 participant majority of them continue to work beyond 10 years. Seventeen workers smoke 10 cigarettes per day and invariably number of workers engaged in healthy habit is far less. Worker with chronic symptoms, like cough, headache is proportionally low, however, alarming symptom in most workers was cough which clearly implicates the inhalation of toxic substance in the ceramic industry.

Table 2. Mean levels of serum MDA, GSH, and nickel in a group of craft workers of the ceramics industry compared with the normal level (control). * $P=<0.05$, ** $P=<0.04$ and $* * * P=<0.05$.

\begin{tabular}{lll}
\hline Analyte & Control & Sample \\
\hline $\mathrm{MDA}-\mathrm{nmol} / \mathrm{ml}$ & $* 2.48 \pm 0.21$ & $* 3.87 \pm 0.28$ \\
$\mathrm{GSH}-\mathrm{mg} / \mathrm{dl}$ & $* * 4.79 \pm 0.73$ & $* * 1.42 \pm 0.18$ \\
$\mathrm{Nickel}-\mu \mathrm{g} / \mathrm{dl}$ & $* * * 1.88 \pm 0.13$ & $* * * 2.82 \pm 0.10$ \\
\hline
\end{tabular}

There was a moderate increase in the MDA and nickel levels in the workers (56\% and $53 \%$, respectively), in relation to the control subjects. However, there were decreased levels $(30 \%)$ of GSH in these workers compared with the control subjects. These findings suggest an increase in oxidative stress that led to a substantial decrease in the level of antioxidants in the serum of these workers.

Table 3. Mean levels of antioxidant compounds and nickel in the serum of factory workers employed in the ceramics industry. $* P=<0.04, * * P=<0.05$.

\begin{tabular}{llll}
\hline \multirow{2}{*}{ Analyte } & \multicolumn{3}{l}{ Sample } \\
\cline { 2 - 4 } & 1 to 5 Year & 6 to 10 Year & $>$ 10 Year \\
\hline $\mathrm{GSH}-\mathrm{mg} / \mathrm{dl}$ & $* 3.97 \pm 0.16$ & $2.53 \pm 0.14$ & $* 1.64 \pm 0.13$ \\
$\mathrm{Nickel}-\mu \mathrm{g} / \mathrm{dl}$ & $* * 1.94 \pm 0.11$ & $2.84 \pm 0.7$ & $* * 2.98 \pm 0.8$ \\
\hline
\end{tabular}

The antioxidant level was shown to decrease, with a concomitant increase in nickel concentration, as the duration of the employment increased. After 10 years of service in the industry, subjects showed a critically depleted level of antioxidants, with levels at $41 \%$, compared to that in workers with less than 5 years of service. There was a $54 \%$ increase in the levels of nickel in subjects with a length of service greater than 10 years. These subjects also showed depletion of GSH levels, which is clearly indicative of oxidative stress.

Table 4. Mean levels of serum MDA and nickel in a group of workers employed at the ceramics industry in relation to the duration of employment. $* P=<0.04, * * P=<0.05$.

\begin{tabular}{llll}
\hline \multirow{2}{*}{ Analyte } & Sample & & \\
\cline { 2 - 4 } & 1 to 5 Year & 6 to 10 Year & $>$ 10 Year \\
\hline $\mathrm{MDA}-$ & $* 2.95 \pm 0.17$ & $3.96 \pm 0.18$ & $* 4.68 \pm 0.17$ \\
$\mathrm{nmol} / \mathrm{ml}$ & $* * 1.94 \pm 0.11$ & $2.84 \pm 0.7$ & $* * 2.98 \pm 0.8$ \\
$\mathrm{Nickel}-\mu \mathrm{g} / \mathrm{dl}$ & $*{ }^{2}$ & \\
\hline
\end{tabular}

An increase in the duration of employment led to a $54 \%$ increase in nickel levels, which in turn led to the production of MDA from lipid peroxidation of polyunsaturated fatty acids. As soon as the inhaled nickel particles reach the lungs, they induce damage to the cell membrane of the lung parenchyma; however, the molecular mechanism of this toxic event causing cellular injury remains to be elucidated.

Table 5. Lung functions in factory workers employed in the ceramics industry. Mean value. ${ }^{*} P=<0.05$.

\begin{tabular}{lllll}
\hline $\begin{array}{l}\text { Lung } \\
\text { functions }\end{array}$ & $\begin{array}{l}\text { Normal } \\
\text { adult male }\end{array}$ & $\begin{array}{l}\text { 1 to 5 year } \\
\text { duration of } \\
\text { employment }\end{array}$ & $\begin{array}{l}\text { 6 to 10 year } \\
\text { duration of } \\
\text { employment }\end{array}$ & $\begin{array}{l}\text { > 10 year } \\
\text { duration of } \\
\text { employment }\end{array}$ \\
\hline $\mathrm{FVC}-$ Liter & $5 \pm 0.5$ & $4.6 \pm 0.2$ & $4.4 \pm 0.4$ & $4.3 \pm 0.7$ \\
$\mathrm{FEV}_{1}$ - Liter & $4 \pm 0.4$ & $3.5 \pm 0.3$ & $3.1 \pm 0.4$ & $2.8 \pm 0.6$ \\
$\mathrm{FEV}_{1} / \mathrm{FVC}-\%$ & $* 80 \% \pm 7 \%$ & $76 \% \pm 5 \%$ & $70 \% \pm 8 \%$ & $* 65 \% \pm 5 \%$ \\
\hline
\end{tabular}

Table 1 illustrates the lung functions of the factory workers. It was imperative to demonstrate whether factory workers exposed to toxic levels of nickel could have their lung function compromised. We therefore measured the FVC and $\mathrm{FEV}_{1}$. The $\mathrm{FEV}_{1} / \mathrm{FVC}$ ratio was compared with that in normal adults, and it was found that as the duration of employment in the factory increased, this ratio progressively decreased, and it was found to be $65 \%$ in workers who had been working for over 10 years. This suggests compromised lung function following such chronic exposure to the metal. Thus, all individuals with 10 or more years of employment in the factory complained of frequent irritating cough and frequent visits to the doctor (data not shown). Workers with a history of smoking were excluded from this experiment to avoid confounding bias. However, they were included in all other measurements conducted in the study.

Table 6. Mean level of antioxidant compounds and the ratio of forced expiration volume in $1 \mathrm{~min} /$ forced vital capacity $\left(F E V_{1} / F V C\right)$ ratio. $* P=<0.04, * * P=<0.05$.

\begin{tabular}{lllll}
\hline \multirow{2}{*}{ Analyte } & \multirow{2}{*}{ Control } & \multicolumn{2}{l}{ Sample } & \\
\cline { 3 - 5 } & & $\mathbf{1}$ to 5 Year & $\mathbf{6}$ to 10 Year & $>$ 10 Year \\
\hline $\mathrm{GSH}-\mathrm{mg} / \mathrm{dl}$ & $* 4.79 \pm 0.73$ & $3.97 \pm 0.16$ & $2.53 \pm 0.14$ & $* 1.64 \pm 0.13$ \\
$\mathrm{FEV} / \mathrm{FVC}-\%$ & $* * 80 \pm 7$ & $76 \pm 5$ & $70 \pm 8$ & $* * 65 \pm 5$ \\
\hline
\end{tabular}

The antioxidant level decreased with decreased performance in the lung function tests, associated with an increase in the duration of employment. After 10 years of working, there was a critical depletion of the antioxidant level to $41 \%$, and lung function decreased to $20 \%$ of the 
normal ratio and to $11 \%$ in relation to the level of subjects working for 5 years in the factory.

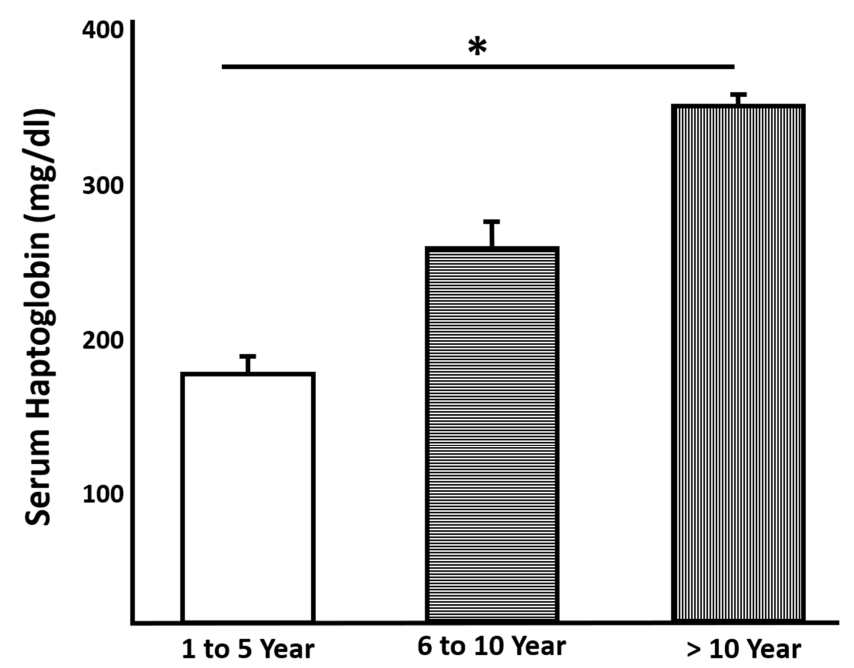

Figure 1. Mean increase in haptoglobin levels as the duration of employment of factory workers increases. $* P=<0.05$.

As documented earlier, nickel binds to a diverse repertoire of proteins, and most importantly to $\mathrm{Hp}$ [20]. In our study, we observed a concomitant increase in the level of Hp in factory workers as their exposure to nickel and duration of employment increased (Figure 1).

\section{Discussion}

In this study, we have demonstrated the increase of serum nickel level in the ceramic industry worker, as their work duration increases, serum level of nickel has already been reported earlier [29, 30]. This increased level contemplates the changes in the MDA and glutathione level in the serum and at the molecular level Hp levels increase as the work duration of the worker increases. These impeccable findings clearly had its effect on the pulmonary function of the workers, which was demonstrated with the lung function test. In our study work duration is clearly associated with increased nickel and MDA level with decreased GSH. This finding concomitantly impairs the lung functions of workers.

Inhalation of toxic fibers by factory workers has been a critical issue in third-world countries, especially in those where protective measures have not been taken. In Pakistan, these issues have been addressed; however, authorities have failed to implement efficient measures throughout the industrial sector. Craft workers in the ceramics industry are exposed to high levels of hazardous toxic substances such as silica and $\mathrm{SiO}_{2}$, which cause a restrictive lung disease known as silicosis [31].

Occupational exposure results in elevated levels of nickel in blood and urine, and inhalation is the main route of uptake $[3,32]$. The same results have been observed in our study in which craft workers in the ceramics industry were progressively exposed to soluble nickel. Furthermore, as the duration of employment increased, the levels of nickel in the blood increased as well, eliciting a stress response that leads to decreased levels of antioxidants (Table 2). Work intensity and stress lead to oxidative stress [33]. We have obtained similar results in this study as well. As the length of service of a worker in the ceramics industry increases, the body becomes more vulnerable to oxidative stress (Tables 3 and 4).

It has been proposed that the imbalance between the generation of free radicals and the activity of antioxidants causes oxidative stress. Mild oxidative stress can be tolerated, but a higher level of imbalance may result in a number of diseases [34]. The increased concentration of soluble metals can be the cause for the development of oxidative stress and the generation of free radicals that can directly bind with the thiol groups of antioxidant enzymes. Furthermore, it can generate DNA lesions, leading to cancer. Nonetheless, increased risk for lung cancer was found in studies conducted in different European countries [34]. We observed an increased MDA level and decreased antioxidant level with continuous exposure to soluble nickel particles in our study as well.

Further, we illustrated how the exposure of fiber craft workers to nickel and the stress induced by excessive nickel inhalation reduce the levels of antioxidants in serum, eventually compromising the respiratory system. Furthermore, continuous exposure can increase the Hp level to toxic proportions, thereby causing lung cancer, as reported earlier by a group of researchers $[18,19]$.

One of the imperative associations of Nickel in our study was its effect on the Hp that fluctuate as the duration of work increase. The other positive finding we had was the changes in the functional capacities of the lungs measured, using spirometer. Regardless to these finding, the limitations of this study include the small number of subjects from only one factory. Further studies with larger samples are needed to determine the effects of other metal ions on the health status of workers.

\section{Conclusion}

We conclude that the high nickel levels in workers of a fiberglass factory are responsible for increased antioxidants levels in their body, which in the long run may potentiate the development of diseases, especially of the respiratory tract. There is a need for national and international help to frame appropriate guidelines for workers working in such hazardous environments. Precautionary measures like wearing gloves and masks, hand washing, and the use of hand sanitizers may protect them from the effects of these chemicals. Failure to control exposure to heavy metals may result in severe complications in the future because of their adverse effects.

\section{Ethics Approval and Consent to Participate}

Approved by the Ethics committee of the IMBB, of The University of Lahore (UOL) on 28/05/2019 under the reference number; IMB/UOL/19/323. Informed consent from 
the participant was obtained during the sampling.

\section{Conflict of Interest}

The authors declare that they have no competing interests.

\section{References}

[1] Hancu BD, Pop M. Assessment of health effects related to fiber glass exposure in fiber glass workers: exhaled biomarkers eCO, FENO and their usefulness in the occupational environment testing. Clujul Medical. 2013; 86: 114-116.

[2] Shannon H, Muir A, Haines T, Verma D. Mortality and cancer incidence in Ontario glass fiber workers. Occup Med. 2005; 55: 528-534.

[3] Meeting of the NTP Board of Scientific Counselors Report on Carcinogens Subcommittee. U.S. Department of Health and Human Services. Final Report on Carcinogens, Background Document for Metallic Nickel and Certain Nickel Alloys. Research Triangle Park, NC. 2000. pp. 1-6.

[4] Tundermann JH, Tien JK, Howson TE. Nickel and Nickel Alloys. In: Kirk-Othmer Encyclopedia of Chemical Technology. https://doi.org/10.1002/0471238961.

[5] IARC I. monographs on the evaluation of carcinogenic risks to humans, Arsenic, Metals, Fibres, and Dusts. Nickel Nickel Compd. 2012; 100: 175-181.

[6] Fay. M. Toxicological Profile for Nickel. Atlanta, GA: US Public Health Service, Agency for Toxic Substances and Disease Registry. 2005. pp. 3-6.

[7] WHO. Nickel in Drinking Water. WHO/SDE/ WSH/07.08/55. Geneva: World Health Organization. 2007.

[8] EVM. Expert Group on Vitamins and Minerals: Revised Review of Nickel. EVM. 2002; 99: 24.

[9] R. Maheshwari and R. S. Dubey, "Nickel-induced oxidative stress and the role of antioxidant defence in rice seedlings," Plant Growth Regulation. 2009; 59: 37-49.

[10] Harris GK1, Shi X. Signaling by carcinogenic metals and metal-induced reactive oxygen species. Mutation Research/Fundamental and Molecular Mechanisms of Mutagenesis. 2003; 10: 183-200.

[11] Badding MA, Fix NR, Antonini JM, Leonard SS. A Comparison of Cytotoxicity and Oxidative Stress from Welding Fumes Generated with a New Nickel-, Copper-Based Consumable versus Mild and Stainless Steel-Based Welding in RAW 264.7 Mouse Macrophages. PLoS ONE. 2014; 9: e101310.

[12] Valko M, Jomova K, Rhodes CJ, Kuča K, Musílek K. Redoxand non-redox-metal-induced formation of free radicals and their role in human disease. Arch Toxicol. 2016; 90: 1-37.

[13] Reyazuddin M, Azmi SA, Islam N, Rizvi A. Oxidative stress and level of antioxidant enzymes in drug-naive schizophrenics. Indian J Psychiatry. 2014; 56: 344-349.

[14] Goulart M, Batoreu M, Rodrigues A, Laires A. \& Rueff J. Lipoperoxidation products and thiol antioxidants in chromium exposed workers. Mutagenesis. 2005; 20: 311-315.
[15] Halliwell, B. Free radicals and antioxidants - Quo vadis? Trends in Pharmacological Sciences. 2011; 32: 125-130.

[16] Taruna I, David AS, Terawan AP. Atypical Levels of Heavy Metals, Creatinine, Haptoglobin, and Ferritin Found in Amyotrophic Lateral Sclerosis Outpatients Vs. Healthy Controls: Possible Utility as a Diagnostic Biomarker Int J Pathol Clin Res 2019: 5: 091.

[17] Mahdi A, Holger S, Daniel K, Detlev B, Klaus D, Peter Z, et al. Expression of the acute phase protein haptoglobin in human lung cancer and tumor free lung tissues. Torsten Goldmann Pathology - Research and Practice. 2009: 205: 639647.

[18] You-Kang C, Yu-HL, Yen Chu, Ming-CL, Chun-Yao H, and Semon Wu. Haptoglobin is a serological biomarker for adenocarcinoma lung cancer by using the ProteomeLab PF2D combined with mass spectrometry. Am J Cancer Res. 2016; 6: $1828-1836$.

[19] Kang SM, Sung HJ, Ahn JM, Park JY, Lee SY, Park CS, et al. The Haptoglobin $\beta$ chain as a supportive biomarker for human lung cancers. Mol Biosyst. 2011; 7: 1167-75.

[20] Barbara J. Scott and Arthur R. Bradwell. Identification of the Serum Binding Proteins for Iron, Zinc, Cadmium, Nickel, and Calcium. Clinical Chemistry. 1983; 29: 629-633

[21] Šimková, J, Milkovičová, M, Valko-Rokytovská, M, Kostecká, Z, Bencúrová, E. et. al. Analysis of nickel-binding proteins from various animal sera. Folia Veterinaria. 2018; 62: 59-66.

[22] Birben E, Sahiner UM, Sackesen C, Erzurum S, Kalayci O. Oxidative stress and antioxidant defense. World Allergy Organ J. 2012; 5: 9-19.

[23] Alberto S, Davide DM, Alessandro M, Sergio I. Nickel Compounds in the Workplaces: Occupations and Activities Involving High-Risk Exposures in Italy. Am J Ind Med. 2018; 12: 968-977.

[24] Jeyamala S, Kumaraguru AK, Nagarani M. Occupational health effects due to nickel and chromium exposure in electroplating workers. Toxicological \& Environmental Chemistry. 2012; 94: 1583-1590.

[25] Boran A, Al-Hourani Z, Al-Balwi A, Muhammad M, Bello A, et al. Occupational exposure to nickel, cadmium and copper among workers in jewelry manufacturing European Scientific Journal. 2014; 10: 150-159.

[26] Vehbi B, Agron V, Mentor S. Determination Method of High Content of Nickel in Ferronickel and Various Alloys Using Atomic Absorption Spectrometry. J. Int. Environmental Application \& Science. 2018: 13: 174-179.

[27] Tietze F. Enzymic method for quantitative determination of nanogram amounts of total and oxidized glutathione: applications to mammalian blood and other tissues. Anal Biochem. 1969; 27: 502-522.

[28] Okhawa H, Ohishi N, Yagi K. Assay for lipid peroxidases in animal tissues by thiobarbituric acid reaction. Anal Biochem. 1979; 95: 351-358.

[29] Anna M. G, Maria T. L, Luciana P. Determination of nickel in the serum of occupationally exposed workers, by means of flame atomic-absorption spectroscopy. Talanta. 1985: 32: 949-952. 
[30] Nadica T, Irina K, Trajce S. ETAAS determination of nickel in serum and urine. Anal Bioanal Chem. 2002: 373: 310-313.

[31] Doan JH. Health Hazards in Arts and Craft. The Work Environment and Indoor Health Hazards. Lawrence W. Whitehead. Lewis Publishers. 1994; 3: 67-69.

[32] Lyon FR. The International Agency for Research on Cancer (IARC). Chromium, Nickel and Welding. IARC Monographs on the Evaluation of Carcinogenic Risks to Humans. 1990; 49: 283-300. PMID: 2232124.
[33] Zelzer S, Tatzber F, Herrmann M, Wonisch W, Rinnerhofer S, et. al. Work Intensity, Low-Grade Inflammation, and Oxidative Status: A Comparison between Office and Slaughterhouse Workers. Oxid Med Cell Longev. 2018; 2018: 2737563.

[34] Sakac V, Sakac M. Free oxygen radiacals and kidney diseases part I. Med Preg. 2000; 53: 463-474. 